\title{
De Concesiones Lineales a Contratos de Gestión Zonales: Una Propuesta para el Transporte Público Interurbano de Viajeros por Carretera en Aragón
}

\author{
From Linear to Zonal Management Contracts: A Proposal for the Public \\ Inter-Urban Transportation of Travelers by Road in Aragón \\ Ricardo Badía-Lázaro \\ rbadia@unizar.es@ https://orcid.org/0000-0003-0572-3681 \\ Eugenio Climent-López \\ ecliment@unizar.es @ https://orcid.org/0000-0001-6788-4873 \\ Grupo de Estudios de Ordenación del Territorio (GEOT). Universidad de Zaragoza \\ Departamento de Geografía y Ordenación del Territorio \\ Universidad de Zaragoza. C/ San Juan Bosco, $n^{\circ}$ 7. 50009 - Zaragoza
}

\section{INFO ARTÍCULO}

Recibido: 10/4/2019

Revisado: 21/5/2019

Aceptado: 24/5/2019

\section{PALABRAS CLAVE}

Transporte público

Autobús

Interurbano

Accesibilidad rural

Contrato de gestión

\section{KEYWORDS}

Public transportation

Bus

Inter-urban

Rural accessibility

Management contract

\section{RESUMEN}

El objetivo del artículo es presentar una propuesta de reestructuración del sistema de transporte interurbano de viajeros por carretera en Aragón, a partir del diagnóstico previo. Para ello se recurre a diversas fuentes de información y se utilizan técnicas de análisis espacial. Se constata la dificultad de prestar un servicio de transporte de calidad en regiones de baja densidad demográfica y dispersión del poblamiento y se identifican las ineficiencias del actual sistema de concesiones lineales. Se propone un nuevo sistema de concesiones zonales, que permite mayor coordinación e integra transporte regular y escolar. La propuesta se valora económicamente y se contrasta con los planes de la administración regional.

\begin{abstract}
The objective of the article is to present a proposal for the restructuring of the interurban transportation system of travellers by road in Aragón, based on a previous diagnosis. Several sources of information and spatial analysis methods are used. The difficulty of providing a quality transport service in regions of low population density and settlements dispersion is noted and the inefficiencies of the current system of linear concessions are identified. A new system of zonal concessions is proposed, which allows for greater coordination and integrates general and school transportation. The proposal is valued economically and compared with the plans of the regional administration.
\end{abstract}




\section{INTRODUCCIÓN}

Dentro del amplio campo de investigación de la geografía del transporte, este trabajo se ubica en una parcela a la que se ha prestado poca atención, en comparación con otras: el transporte público interurbano de personas por carretera.

El transporte público de viajeros hace posible y garantiza un derecho ciudadano fundamental: la libre circulación de personas (Belintxon, U., 2016, 20). Todos los modos de transporte contribuyen a ello, teniendo cada cual su funcionalidad propia. El transporte interurbano por carretera posibilita la movilidad de los ciudadanos a diferentes escalas espacio-temporales, pero es en las distancias cortas o medias donde tiene una ventaja insuperable respecto a los demás modos: la capilaridad, es decir, la posibilidad de llegar a todas partes, pues los vehículos gozan de una amplia autonomía de movimientos y las redes de carreteras son las de mayor longitud y densidad, con notable ventaja respecto al ferrocarril.

Además de ser la garantía de un derecho ciudadano, el transporte de pasajeros juega un papel fundamental en el funcionamiento de una sociedad cohesionada: "una mayor justicia social no puede ser alcanzada sin una mayor inclusión social, la cual requiere que la gente tenga acceso a un conjunto de actividades consideradas como típicas de su sociedad; una mayor inclusión social requiere una mayor accesibilidad que a menudo implica movilidad y uso de transporte" (Farrington, J. y Farrington, C., 2005, 2).

La Estrategia Territorial Europea (ETE) parte de tres principios de desarrollo territorial, el segundo de los cuales es el acceso equivalente a las infraestructuras y al conocimiento. Dicho principio se desarrolla en los siguientes términos: "Las ciudades y áreas metropolitanas deben conectarse de manera eficaz no sólo a la economía mundial, sino también entre sí y con sus zonas de influencia. Además, el buen funcionamiento de los transportes y un acceso suficiente a las telecomunicaciones son condiciones básicas para el refuerzo de la competitividad de las regiones periféricas o las menos favorecidas y, por lo tanto, de la cohesión económica y social de la UE" (Comisión Europea, 1999, 28). Si bien la ETE se centra principalmente en las infraestructuras, de interés preferente siempre para las administraciones públicas (Garrido, 2002), también propugna el uso eficaz y sostenible de las mismas, mostrando preocupación por la contaminación atmosférica y la congestión del tráfico. Una de las medidas propuestas para aliviar ambos es la mejora del transporte público.

En la misma línea que la ETE, la Estrategia de Ordenación Territorial de Aragón (EOTA) establece como objetivo cuarto "facilitar las condiciones de movilidad y accesibilidad de las personas y bienes" (Gobierno de Aragón, 2014, 39110). Las estrategias y normas formuladas para alcanzar dicho objetivo se centran de manera destacada en las infraestructuras, confirmando que "en la mayoría de las ocasiones, los esfuerzos de las administraciones públicas para mejorar la accesibilidad entre los asentamientos centran su atención casi exclusivamente en la creación y mantenimiento de las infraestructuras viarias, tratando de disminuir el tiempo y los riesgos asociados a la movilidad" (Pons, J. y Betelu, A., 2004, 217). Pero la EOTA no olvida los servicios de transporte, recomendando la redacción de una directriz, que debería tener en cuenta diversos factores, entre ellos "la mejora del sistema de transporte colectivo por carretera de Aragón mediante una nueva propuesta de Concesiones Administrativas de la Gestión del Servicio de Autobús" (Gobierno de Aragón, 2014, 39115).

En tanto que garante de un derecho y favorecedor de una sociedad cohesionada, el transporte de pasajeros puede considerarse un servicio público, respecto al cual el Estado tiene la última responsabilidad. Lo habitual es que el transporte interurbano de viajeros en autobús lo presten empresas privadas en régimen de concesión, según la terminología tradicional, o contrato de gestión, en su denominación actual. Esto significa que las administraciones públicas, por una parte, establecen las rutas que deben seguir los autobuses y las condiciones generales en que debe prestarse el servicio y, por otra, conceden la explotación comercial de dichas líneas a empresas privadas, mediante concurso competitivo. En España las competencias administrativas recaen en el Gobierno central, para el transporte entre comunidades autónomas, y en los Gobiernos regionales, para el transporte interior comunitario.

El transporte interurbano de viajeros en autobús debe planificarse en función de las necesidades de la población, buscando ante todo la rentabilidad social. Por ello la planificación debe prever una "oferta equilibrada de transporte público, adecuada a las necesidades de desplazamiento de todos los individuos y que 
permita, en primer lugar, el acceso a la educación, al empleo y a los servicios y, seguidamente, al desarrollo de actividades recreativas y sociales" (Ruiz, M. et al., 2016, 621). Las necesidades de transporte pueden satisfacerse por medios privados, pero "no todos los hogares disponen de vehículo privado, y mucho menos todos los miembros del hogar. Las causas de esta falta de acceso universal al automóvil son muy diversas y abarcan desde la imposibilidad física o mental para conducir, a motivaciones económicas" (Pons, J. y Betelu, A., 2004, 217-218). En aras de la cohesión social, el Estado está obligado a atender especialmente las necesidades de los colectivos menos favorecidos económicamente, así como de los niños, ancianos y demás personas que no disponen de vehículo privado (alrededor de un tercio de la población total). Pero no debe olvidarse tampoco que, en tanto que este tipo de transporte lo prestan empresas privadas, su planificación debe tener en cuenta también la rentabilidad económica (López, E., 1989).

Esa necesidad de atender a los colectivos menos favorecidos se plantea tanto en los espacios urbanos, donde los contrastes sociales son muy marcados (Ruiz, M. et al, 2016; Guirao, B. y Briceño, D., 2006), como en el ámbito rural, donde los principales servicios tienden a concentrarse en un reducido número de lugares centrales (Bachiller, J.M. y Molina, I., 2014), a los que la población tiene que desplazarse necesariamente. En este sentido, "la accesibilidad física y geográfica de los servicios puede ser descrita como el factor primario que condiciona la capacidad de la gente para acceder a ellos" (Smith, N. et al., 2012, 93) y esa capacidad viene dada por la existencia de transporte. Por eso el transporte público de viajeros por carretera es fundamental para que todos los habitantes del medio rural puedan acudir al colegio, al centro de salud, al trabajo, al comercio y a los demás servicios.

\section{1. Ámbito territorial y objetivos}

El ámbito territorial de este trabajo es la Comunidad Autónoma de Aragón. Las concesiones de líneas regulares de autobús, resultado de un cúmulo de decisiones sucesivas tomadas y revisadas a lo largo del último medio siglo, caducaron en el año 2017, abriéndose así la posibilidad de diseñar un mapa totalmente nuevo, con visión de conjunto y adaptado a las necesidades actuales. Los empresarios del sector, anticipándose a dicha fecha, patrocinaron la realización de un estudio para hacer una propuesta de reordenación, partiendo del diagnóstico de la situación vigente. ${ }^{1}$ Los criterios del diagnóstico se establecieron a partir de la condición de servicio público de dicho transporte, según las consideraciones realizadas previamente. La propuesta se basó en la doble premisa de la rentabilidad social y económica: el nuevo sistema de contratos de gestión, por una parte, debe garantizar la movilidad de todos los habitantes de Aragón, sea cual sea su lugar de residencia, permitiéndoles acceder en condiciones adecuadas a los servicios necesarios; por otra parte, debe garantizar unos beneficios razonables a las empresas prestatarias del servicio.

El objetivo de este artículo es dar a conocer la metodología empleada y los resultados más relevantes de dicho estudio, con el deseo de que pueda ser útil para trabajos de similar índole planteados en otros contextos espaciales.

El estudio se estructuró en dos fases: diagnóstico y propuesta. En la primera se analizaron los contratos de gestión y las rutas de autobús existentes, en relación con la distribución espacial de la población, la estructura comarcal y la localización de los principales servicios, especialmente los educativos y sanitarios; asimismo se cuantificaron el coste económico del sistema, los ingresos obtenidos por la venta de billetes y las subvenciones de la administración pública. En la segunda fase se diseñó un sistema de contratos de gestión de carácter zonal. A partir de los resultados del diagnóstico se hizo una delimitación de zonas de transporte, en cada una de las cuales se planificaron rutas de autobús para solucionar los problemas detectados sin incurrir en incremento de costes y procurando llegar a todos los núcleos de población.

1. Se trata del contrato de $I+D+i$ "Análisis y propuestas para la remodelación de las concesiones del transporte de viajeros por carretera en la comunidad autónoma de Aragón", firmado por la Asociación Empresarial de Transportes Interurbanos de Viajeros en Autobuses de Aragón (AETIVA) y la Universidad de Zaragoza en junio de 2014. 


\section{METODOLOGÍA}

El proceso metodológico consta de dos etapas: 1) diagnóstico del sistema actual de transporte y 2) evaluación de propuestas de mejora. La primera etapa se subdivide en dos fases: a) obtención y tratamiento de datos y b) análisis de datos.

La fase de obtención y tratamiento de datos engloba la recopilación y edición de una base de datos espacial con información tanto de la oferta como de la demanda de transporte público. Los datos referidos a la oferta están integrados por dos niveles. El primero lo constituye una tabla referida a todas las rutas de transporte del área, tanto regular como escolar, que recoge su tipología, kilómetros recorridos, coste, número de alumnos y viajeros. Se trata de datos que las empresas contratistas están obligadas a suministrar periódicamente a la Administración y que ha sido utilizada también como fuente de información en otros trabajos sobre las concesiones de transporte (Sánchez, S., 2015, sobre Andalucía; Rojo, M., 2011, sobre Castilla y León). Esta tabla queda integrada en una capa de líneas que permite caracterizar la red de transporte público. Un segundo nivel, más desagregado, es la tabla de servicios, que relaciona los horarios de parada de cada una de las expediciones de estas rutas con los núcleos de población, integrándose en una capa de núcleos, a la que se asignan también los datos referidos a la demanda de transporte, que son las características demográficas de los núcleos de población, su nivel de centralidad y la disponibilidad de servicios escolares y sanitarios.

La segunda fase del diagnóstico consistió en el análisis de estos datos. Por un lado, se hicieron consultas espaciales a la capa de rutas para clasificarlas en función del rango jerárquico de los núcleos que conectan. Por otro lado, se calculó el tiempo de recorrido desde cada localidad a su capital comarcal y cabecera de sector sanitario, utilizando los horarios de paso de cada expedición, y se obtuvo el total de expediciones en cada sentido; estos dos últimos datos (tiempo de recorrido y número de expediciones) se sintetizaron para establecer rangos de calidad del servicio en cada uno de los núcleos. La metodología de esta fase es la habitual en los estudios sobre servicios de transporte, que consideran la accesibilidad en referencia a los núcleos en que se ubican los principales servicios y toman el tiempo como medida de la fricción de la distancia (Gutiérrez, J., 1988 y 2001). En este caso, el tiempo ha sido calculado a partir de los horarios oficiales, no de la velocidad estimada en función de las características de las carreteras, lo cual suele hacerse al estudiar el transporte en vehículo privado o al valorar la importancia de las infraestructuras (Martínez, H. S., 2012, para el caso de Castilla La Mancha; Mora, J. et al., 2003, para el de Extremadura).

La segunda etapa del proceso metodológico es la propuesta de mejora del servicio, mediante la delimitación de zonas de transporte. A la propuesta final se ha llegado de forma iterativa mediante un proceso que consta de las siguientes fases:

En primer lugar, se ha realizado una delimitación apriorística de zonas de transporte atendiendo a los siguientes criterios derivados del diagnóstico:

a. Existencia de líneas estructurantes que canalizan la mayor parte de los flujos de transporte interno en la zona, articulando un eje que debe actuar como la columna vertebral de cada zona de transporte.

b. Existencia a lo largo de dichos ejes de núcleos de población que funcionan como lugares centrales de áreas de influencia bien definidas.

c. Existencia de áreas funcionales definidas según criterios de prestación de servicios, principalmente sanitarios y educativos.

En segundo lugar, se ha diseñado la reordenación del transporte de viajeros en cada una de las zonas; esto permite establecer, por un lado, una valoración cualitativa de las características y la estructura del transporte de viajeros y, por otro, una cuantificación de las principales variables e indicadores del sistema de transporte. En tercer lugar, se ha hecho el ajuste y propuesta definitiva de zonas de transporte. Finalmente, la valoración económica de cada una, comparando la situación actual y la resultante de la reordenación. 


\section{DIAGNÓSTICO DEL TRANSPORTE REGULAR INTERURBANO DE VIAJEROS EN AUTOBÚS DE ARAGÓN}

El diagnóstico del transporte regular interurbano de viajeros en autobús de Aragón se expone en tres pasos: en primer lugar, la distribución espacial de la población, en términos de densidad demográfica y modelo de poblamiento. A continuación, la estructura del sistema actual de transporte, identificando y caracterizando las concesiones y líneas regulares existentes. En tercer lugar, la valoración de la calidad del servicio prestado a los usuarios y su valoración económica.

\subsection{Distribución espacial de la población y modelo de poblamiento}

La organización del servicio público de transporte de viajeros por carretera está condicionada por la distribución espacial de la población, es decir, por la densidad demográfica y la estructura del sistema de poblamiento.

En el territorio aragonés viven 1.308.728 habitantes -según el padrón municipal a 1 de enero de 2018sobre una superficie de $47.720 \mathrm{~km}^{2}$. Esto da lugar a una densidad de 27 habitantes por $\mathrm{km}^{2}$, una de las más bajas de España. Pero a la vez presenta fuertes desequilibrios territoriales: por una parte, en 480 de sus 731 municipios la densidad es inferior a diez habitantes por $\mathrm{km}^{2}$, considerado como "límite de despoblación severa" (Delgado, J. M., 2018, 269). Por otra, en el área metropolitana de Zaragoza se concentran 744.579 personas, el $57 \%$ de la población regional, en sólo el $5 \%$ del territorio. Esta situación de concentración y a la vez despoblación, típica del interior de España, dificulta la prestación de un transporte público de calidad, afectando principalmente a la movilidad de la población rural, como ha sido puesto en evidencia, por ejemplo, en el caso de la provincia de Albacete (Fernández, F., 1999).

El sistema de poblamiento condiciona la demanda de transporte público de viajeros. En aquellas áreas donde la densidad de asentamientos es alta, se necesitan más rutas de transporte para poder atender a la población. Combinando densidad de población y densidad de núcleos se identifican cuatro tipos de zonas, cada una de las cuales demanda servicios de transporte de diferentes características (mapa 1).

- Densidad de población baja, sea cual sea la densidad de núcleos: son las zonas que plantean las mayores dificultades para asegurar un servicio de transporte de calidad, por la limitación de la demanda. En ellas habita el 3\% de la población aragonesa, pero se ubica el $40 \%$ de los núcleos de población. Representadas en el mapa con tonos amarillos y anaranjados, se extienden especialmente por el norte de la provincia de Huesca y la práctica totalidad de la de Teruel.

- Densidad de población media y densidad de núcleos media-alta: se trata de espacios en los que la población se asienta en muchos núcleos relativamente pequeños y dispersos, por lo que las distancias entre ellos son cortas. Esto obliga a diseñar un elevado número de rutas, con muchas paradas, aunque la demanda es baja, lo que hace muy difícil que las frecuencias sean altas. En ellas habita el $8 \%$ de la población aragonesa y se localiza el 33\% de los núcleos. Se corresponden con las zonas rosadas del mapa, que engloban buena parte del somontano pirenaico y la Comunidad de Calatayud.

- Densidad de población media-alta y densidad de núcleos baja: en estos espacios encontramos mayor población, concentrada en pocos núcleos. La demanda de transporte es moderada, pero puede ser satisfecha con un número de rutas relativamente bajo, posibilitando la existencia de un servicio de transporte adecuado. Estos espacios, muy poco extendidos en Aragón, aparecen con tonalidades verdes en el mapa; en ellos vive el 7\% de la población y se localiza el 5\% de los núcleos.

- Densidad de población alta y densidad de núcleos media-alta: Implica una alta demanda de transporte de viajeros, creándose un escenario parecido al de los espacios urbanos, con muchas rutas, numerosas paradas y frecuencias altas. En estas zonas habita el $82 \%$ de la población regional y en ellas se ubica el $21 \%$ de los núcleos. Están representadas con colores azulados y se extienden principalmente por las vías de entrada a la ciudad de Zaragoza, englobando también el resto de núcleos de cierto tamaño. 


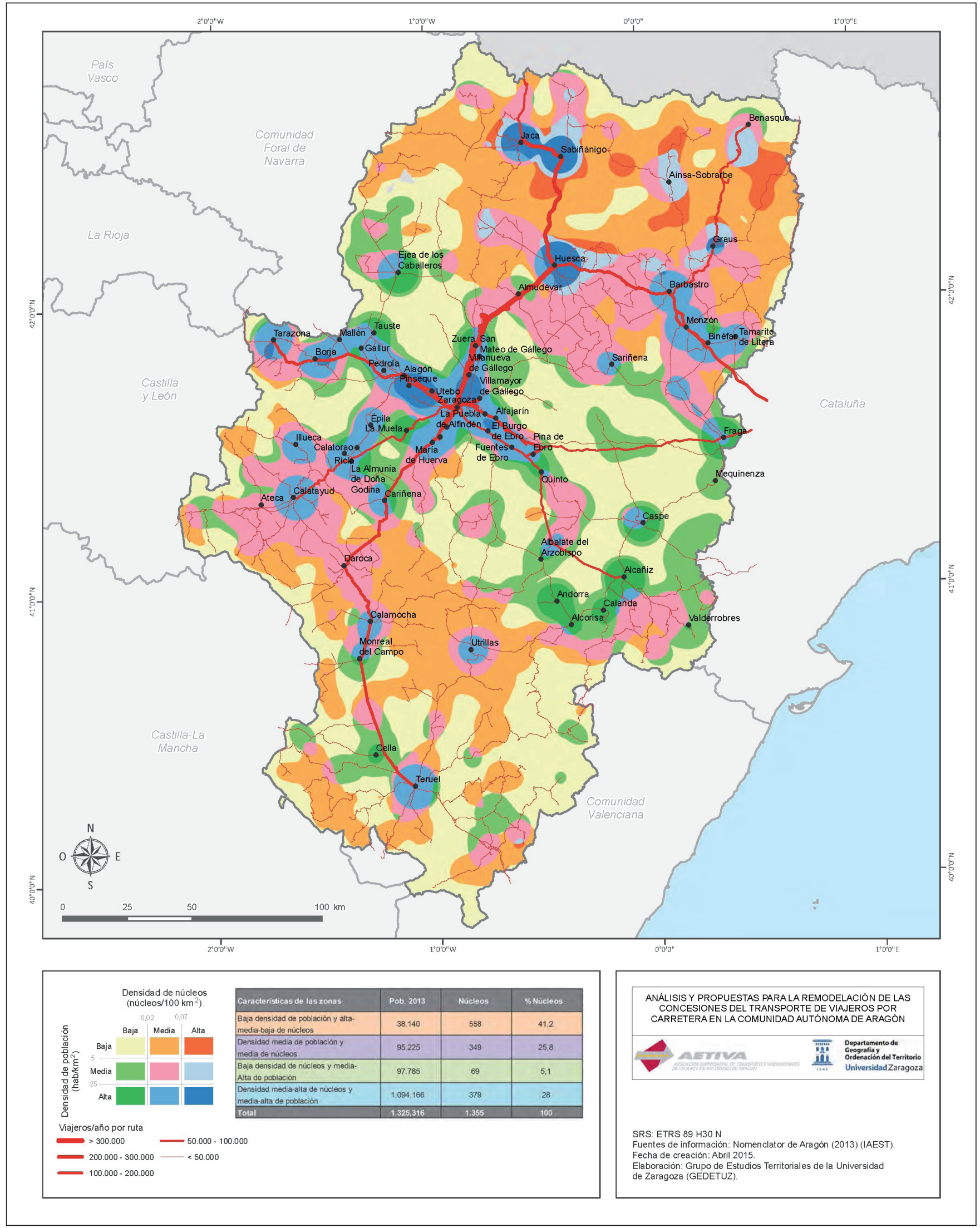

Mapa 1. Densidad de población y densidad de núcleos de población.

Fuente: Nomenclátor y elaboración propia. El procedimiento seguido para la confección del mapa es el utilizado por Escolano, S. y de la Riva, J. (2003, 12). 
La proyección demográfica del Instituto Nacional de Estadística para el período 2018-2033 prevé un ligerísimo crecimiento de la población aragonesa hasta 2024; a partir de ahí se espera un decrecimiento, debido a un saldo vegetativo negativo, compensado sólo parcialmente por un flujo migratorio positivo. Se acentuará el envejecimiento demográfico, es decir, el aumento en la edad media de la población, provocado por el cambio en la estructura por edades (Pérez, J. y Abellán, A., 2018). El decrecimiento se centrará en las provincias de Huesca y, sobre todo, Teruel, previéndose que continúe la concentración progresiva de la población en las capitales provinciales y otros núcleos de cierto tamaño. Estas tendencias influirán en la demanda de usuarios de transporte público, sobre todo en el medio rural, incrementando la extensión de las áreas que presentan una mayor dificultad de prestación del servicio.

\subsection{Estructura de la red}

La red de transporte público interurbano de viajeros en Aragón está compuesta por dos modos de transporte: autobús y ferrocarril. El transporte por carretera es, con amplia diferencia, el más importante con un total de 283.000 expediciones y 15 millones de kilómetros recorridos en el año 2013, frente al ferrocarril con 19.000 expediciones y 3,3 millones de kilómetros. En paralelo existe una importante red de transporte escolar con un escaso nivel de integración con el resto.

El servicio de autobuses interurbanos se organiza en 288 rutas. A causa de la baja densidad de población la mayoría de ellas cuenta con una frecuencia inferior a la diaria, operando únicamente en días alternos o incluso un solo día a la semana. En el lado opuesto el $9 \%$ de las rutas supera los cuatro viajes diarios por sentido.

El sistema es operado por 46 empresas diferentes, 7 de las cuales concentran más del 75\% de los kilómetros recorridos. Los contratos de gestión lineales aseguran a las empresas que una relación entre un origen y un destino determinados sólo puede ser cubierta por esa misma empresa, evitando así situaciones de competencia. Como la red de concesiones ha sido fruto de un proceso no planificado y dilatado en el tiempo se producen numerosos solapamientos entre líneas de diferentes empresas, por lo que existen restricciones de tráfico que segmentan la escasa demanda existente y disminuyen el número de oportunidades de viaje.

Las rutas existentes se han clasificado en dos tipos, atendiendo a la función que desempeñan en el territorio:

a. Rutas estructurantes: son las que conectan entre sí las localidades de mayor centralidad, es decir, la capital regional, las otras dos capitales provinciales y las nueve pequeñas ciudades que funcionan como cabeceras supra-comarcales. Este último rango jerárquico está definido en la Estrategia de Ordenación Territorial de Aragón (EOTA) y lo integran las localidades de entre 10.000 y 25.000 habitantes (excluidas las del área metropolitana de Zaragoza), todas las cuales disponen de servicios para atender a la población de varias comarcas: institutos con una amplia oferta de educación secundaria no obligatoria (tanto modalidades de bachillerato como ciclos de formación profesional) y hospitales o centros de especialidades médicas. ${ }^{2}$ Téngase en cuenta que la Comunidad Autónoma de Aragón está organizada administrativamente en comarcas, creadas por ley y constituidas como entidades locales dotadas de organismos y competencias específicas. Estas rutas estructurantes son pocas, pero forman una malla en el territorio que facilita los desplazamientos de tipo regional. Se caracterizan por ser relativamente largas, circular por los principales ejes de transporte, poseer una velocidad comercial elevada y superar el umbral de 4 expediciones por sentido en día laborable. Son las que tienen mayores volúmenes de tráfico, con un gran número de expediciones y de viajeros (mapa 2).

b. Rutas de centralidad: su función es la de conectar los núcleos de población menores con los núcleos dotados de centralidad, que son aquéllos donde se localizan los principales servicios básicos a la población: educativos, sanitarios, comerciales, administrativos y lúdicos. Forman el conjunto más numeroso (mapa 3). La cantidad de rutas, el área atendida y el número de expediciones es mayor cuan-

2. El Gobierno de Aragón considera que Calamocha es una cabecera supra-comarcal (mapa 2), a pesar de no llegar a 5.000 habitantes y no disponer de servicios sanitarios supra-comarcales. Con ello pretende cubrir parcialmente la falta de ciudades pequeñas que se aprecia en la mitad meridional de Aragón. 


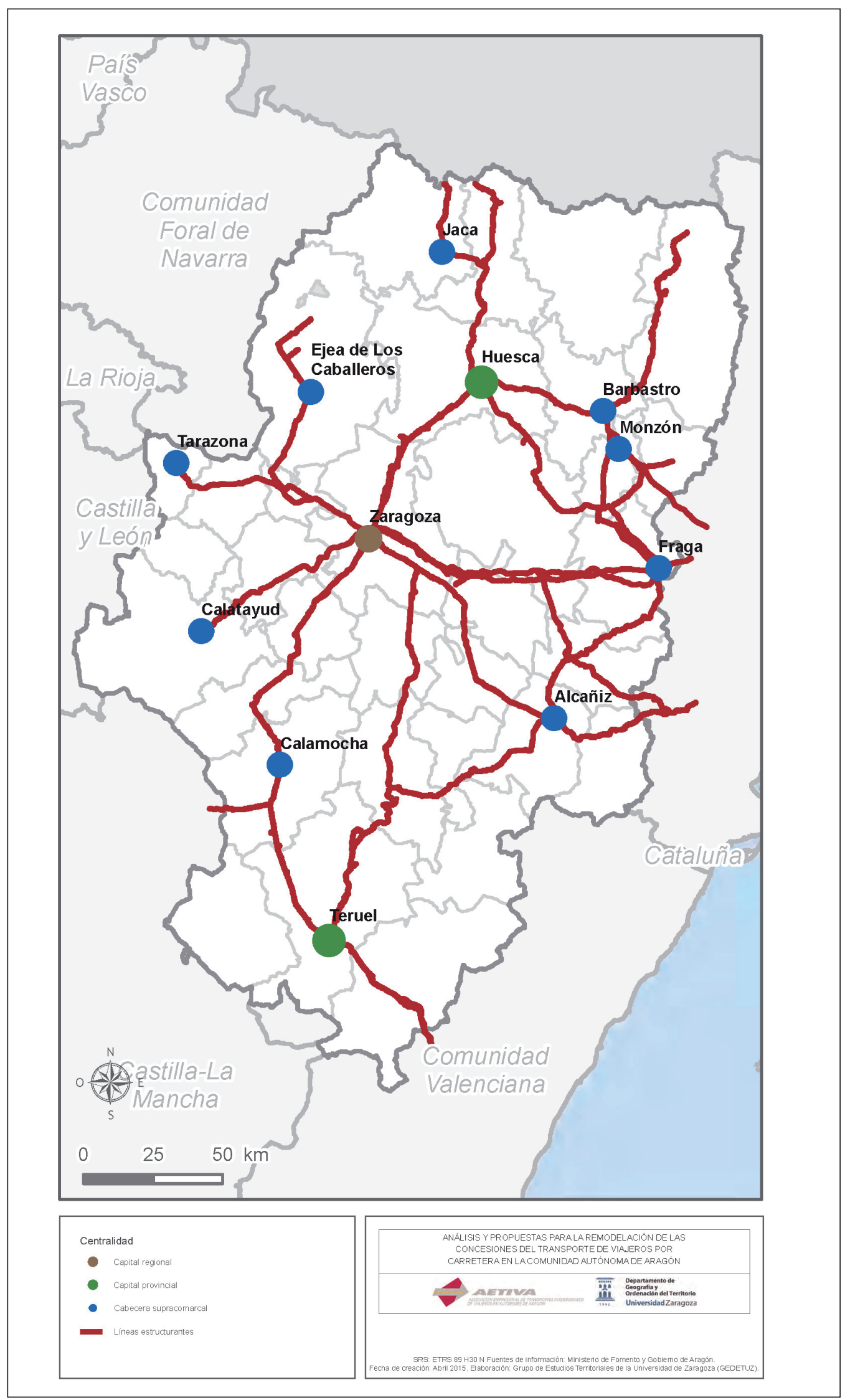

Mapa 2. Rutas estructurantes.

Fuente: Ministerio de Fomento, Gobierno de Aragón y elaboración propia. 


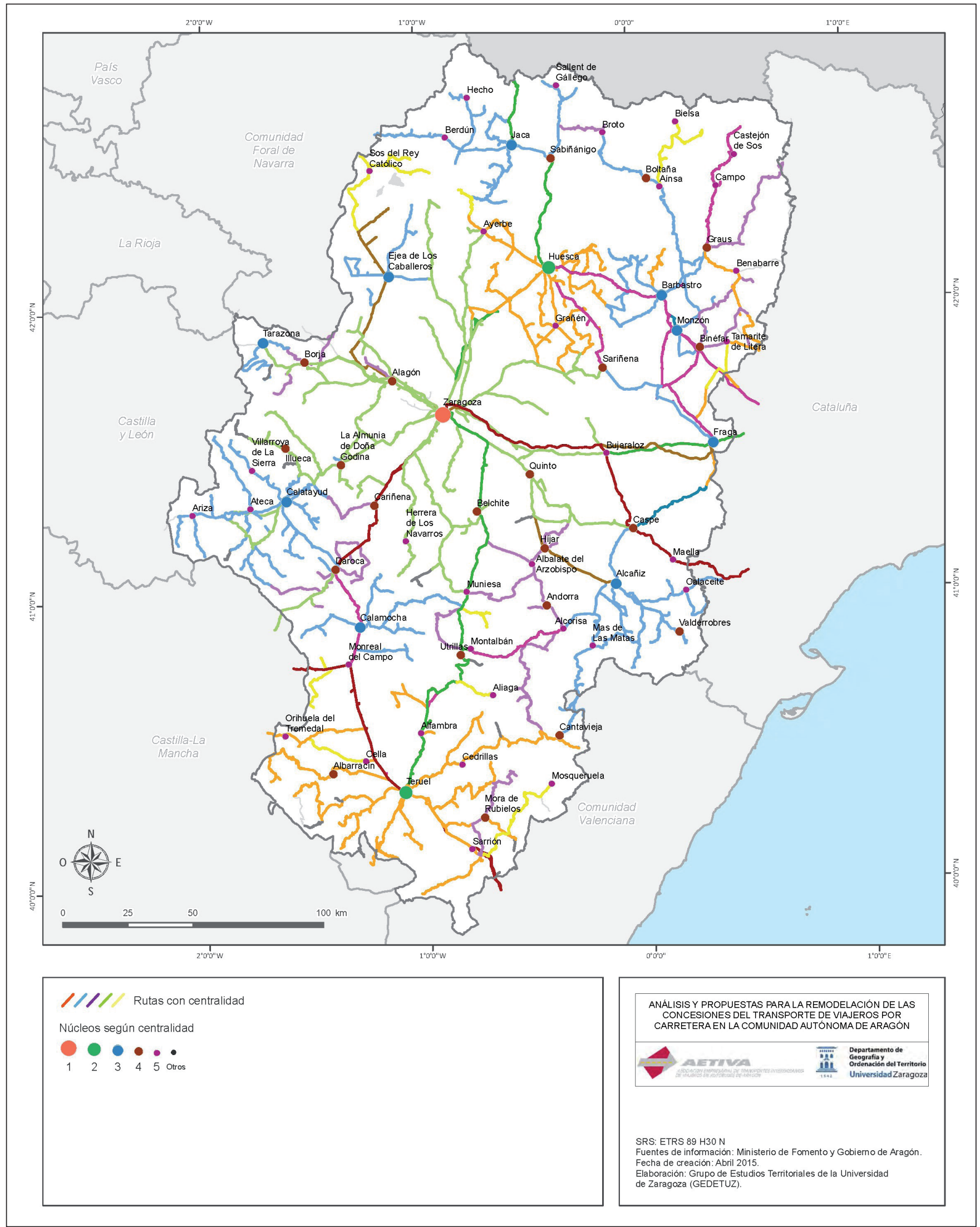

Mapa 3. Rutas de centralidad.

Fuente: Ministerio de Fomento, Gobierno de Aragón y elaboración propia. 
to mayor es el rango de dicho núcleo central. De esta forma, en el entorno de Zaragoza encontramos mayor proporción de rutas con más de 4 frecuencias por sentido, mientras que en las cabeceras de comarca y otros núcleos centrales de carácter sub-comarcal el número de rutas con una única expedición por sentido al día o incluso con expediciones en días alternos es mayor.

En las rutas de centralidad se han observado algunas disfunciones similares a las puestas de manifiesto en trabajos sobre otras regiones: así, en el caso de Murcia "los centros comarcales, con mayor grado de centralidad, son también quienes consiguen un número de líneas y viajes diarios más alto; aunque, en conjunto, el total de los que se dirigen hacia y desde la capital es proporcionalmente superior a su valor en centralidad" (Serrano, J.M., 1987, 633); en Valencia las áreas de influencia delimitadas por las líneas regulares de autobuses no coinciden con las comarcas establecidas para la prestación de determinados servicios (Sanchis, M.C., 1987). En Aragón muchas de las cabeceras comarcales no cuentan con rutas de centralidad en su entorno, dominando claramente las que tienen como destino las capitales de provincia.

En paralelo al servicio general de viajeros encontramos el transporte escolar: Aragón cuenta con 529 rutas y 5,2 millones de viajeros al año, se atiende a 889 núcleos, predominando aquellos de menor volumen demográfico, y supone un coste de 15,8 millones de euros, que es enteramente financiado por las administraciones públicas. Se trata de una red independiente, aunque se ha iniciado un proceso de integración del transporte escolar y regular, que ya afecta al 30\% de las rutas, atendiendo a dos modelos diferentes:

- Las rutas en integración: son rutas escolares que se incorporan a la red de transporte público ofertando las plazas vacías al resto de usuarios. En la actualidad, un $20 \%$ de las rutas escolares se encuentran bajo este sistema. Su principal ventaja es la creación de nuevas expediciones de transporte para el público general en áreas de baja densidad de población.

- Las rutas en reserva de plaza: son rutas en las que los alumnos usan el sistema de transporte público regular junto con el resto de usuarios, mediante reserva previa de sus asientos para todo el curso escolar. Afecta sólo a los alumnos de educación secundaria, que de hecho son más del $80 \%$ de los usuarios del transporte escolar, pues los de infantil y primaria deben viajar siempre en vehículos acompañados de monitores. En la actualidad el modelo de reserva de plaza supone el $10 \%$ del total de servicios escolares y su principal ventaja es la reducción de costes.

La fusión de transporte regular y escolar se da también en otras regiones españolas y en algunos casos ha generado controversia. Por ejemplo, en Galicia ha suscitado críticas, entre otras razones, por la supeditación de los horarios de los centros educativos a la conveniencia de las empresas de transporte (Boquete, D., 2018). En el caso de Aragón el $52 \%$ de los usuarios de autobús afectados se manifiesta indiferente y el $39 \%$ lo considera adecuado; los que no están de acuerdo son sólo el $9 \%$ y sus quejas apuntan en sentido contrario al de Galicia, pues los horarios de los autobuses siempre se supeditan a los horarios escolares; eso perjudica a otros usuarios, como los que se desplazan para hacer compras u otras gestiones, pues la apertura de los comercios se hace sensiblemente más tarde que la de los institutos. ${ }^{3}$

\subsection{Calidad y rentabilidad económica del sistema}

La evaluación de la calidad del servicio de transporte de viajeros por carretera se ha sintetizado mediante la combinación de dos variables: la frecuencia, medida por el número de servicios diarios, y la accesibilidad, expresada en términos de duración del viaje desde cada núcleo de población hasta un municipio dotado de centralidad. Se ha considerado que la calidad del servicio es excelente cuando se dispone de diez o más servicios diarios y el viaje dura menos de 30 minutos; en la medida en que va disminuyendo el número de servicios y aumentando la duración del viaje la calidad va evolucionando a peor (mapa 4).

3. Resultados de la encuesta realizada a los usuarios de autobús en el contexto del contrato de I+D+i mencionado en la nota 1. 


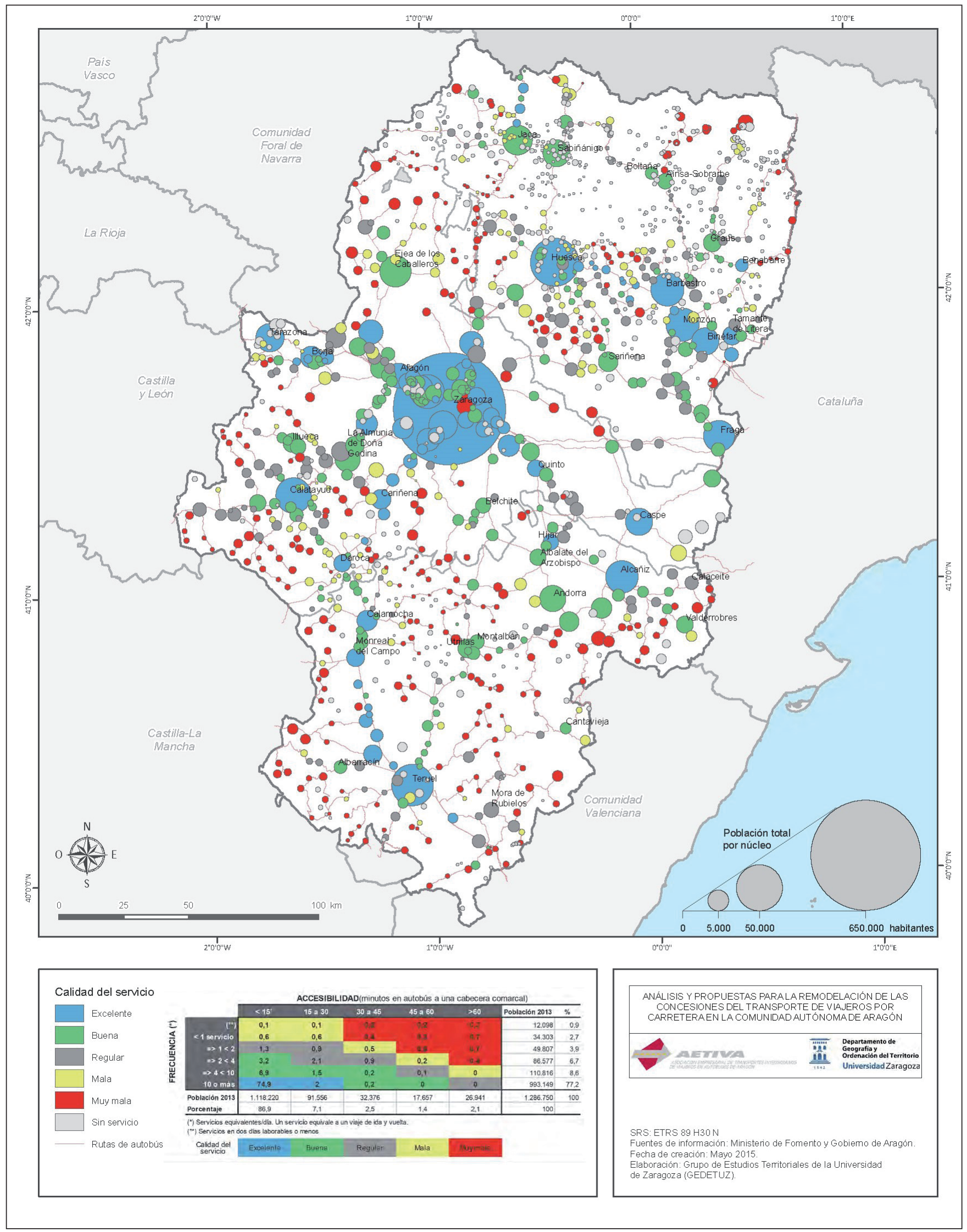

Mapa 4. Calidad del servicio.

Fuente: Ministerio de Fomento, Gobierno de Aragón y elaboración propia. 
Combinando los valores correspondientes a cada núcleo, se concluye que el 77\% de la población aragonesa disfruta de una calidad excelente; se trata mayoritariamente de la que habita en los principales núcleos de población, incluyendo Zaragoza, que por sí sola concentra el 51\% de los habitantes de Aragón. Otro 12\% disfruta de una calidad buena, un $5 \%$ regular, un $2 \%$ mala y un $4 \%$ muy mala. En las dos últimas situaciones se encuentra el $50 \%$ de los núcleos habitados, aunque la población afectada sea reducida.

En cuanto a la rentabilidad, el sistema de transporte regular en autobús moviliza a unos 4 millones de viajeros al año y presenta un coste anual de 20,8 millones de euros. Los ingresos anuales por venta de billetes ascienden a 13 millones de euros, lo que equivale al $63 \%$ de los costes de explotación. Como la recaudación es insuficiente para cubrir los costes y dado que se trata de un servicio público la administración aporta subvenciones a las empresas por valor de 4,2 millones de euros, el 90\% de las cuales procede del Gobierno de Aragón y el $10 \%$ restante de las administraciones locales. Estas subvenciones públicas no cubren totalmente la diferencia entre recaudación y costes, generando un déficit de 3,5 millones de euros, que recae sobre las empresas.

\subsection{Síntesis del diagnóstico}

El diagnóstico realizado pone de manifiesto que el sistema de transporte público de viajeros por carretera de Aragón satisface, en condiciones de calidad, las necesidades básicas de movilidad de una elevada proporción de la población aragonesa, aunque no de toda ni en todas las circunstancias.

Se han puesto de relieve también algunas disfunciones importantes: el estar basado en un número elevado de contratos de gestión lineales da lugar a solapamientos de rutas, con las consiguientes restricciones de tráfico; ello implica un aprovechamiento ineficiente de los recursos disponibles, lo cual repercute en un peor servicio a la población y un mayor coste económico, que en buena medida se ve obligada a asumir la administración pública. Si a ello se añade que el transporte escolar se gestiona de manera independiente, aunque existe cierta coordinación, la ineficiencia se acentúa.

Los mayores problemas se dan en las áreas poco pobladas, con muchos núcleos de población pequeños (mapas 1 y 4); es ahí donde más difícil resulta garantizar la movilidad de las personas en condiciones razonables de calidad. En el resto de las zonas los esfuerzos han de dirigirse a racionalizar al máximo las rutas, evitando duplicidades; ello sería suficiente para mejorar la calidad del servicio y reducir costes.

\section{PROPUESTA PARA EL TRANSPORTE REGULAR INTERURBANO DE VIAJEROS EN AUTOBÚS DE ARAGÓN}

El sistema actual de transporte regular interurbano de viajeros en autobús de Aragón se acomoda con fidelidad, aunque con algunos desajustes, a la jerarquía regional de asentamientos. Como se ha visto, las rutas estructurantes conectan entre sí de forma satisfactoria los núcleos urbanos y la mayor parte de las cabeceras comarcales, mientras que en torno a estos núcleos centrales se organizan rutas de centralidad, que garantizan a los habitantes del área el acceso a los servicios básicos, siendo en ellas donde se aprecian los principales déficits de calidad. Una buena forma de mejorar el sistema es coordinar de forma eficiente las rutas estructurantes y las de centralidad.

La legislación vigente ofrece un instrumento adecuado para realizar esa coordinación: la concesión zonal, prevista en la Ley 16/1987 de Ordenación de los Transportes Terrestres (LOTT). El artículo 78 de la LOTT establece: “Como regla general, las concesiones se otorgarán, únicamente, para servicios predeterminados de carácter lineal; no obstante, la Administración podrá otorgar concesiones zonales que comprenderán todos los servicios regulares permanentes o temporales y de uso general o especial que hayan de prestarse en una determinada zona, salvo los que expresamente se exceptúen". En coherencia con dicha redacción las concesiones lineales son la norma y las zonales la excepción. La ley además indica que al establecer una concesión zonal deben respetarse los derechos económicos de las concesiones lineales ya establecidas. Esta salvaguarda de derechos restringe las posibilidades de su implantación, pero en el caso de Aragón todas las concesiones autonómicas caducaron en el año 2017, estando actualmente en situación de prórroga hasta 
que se publique el nuevo mapa concesional. Esto constituye una gran oportunidad para la realización de un diseño global de contratos de gestión zonales.

Una concesión de este tipo incluye todos los servicios de uso general o especial, aunque se pueden exceptuar algunos expresamente; entre los de uso especial ocupa un papel destacado el transporte escolar, por lo que la coordinación de ambos en la misma zona aseguraría el uso más eficiente de los recursos disponibles. Existen precedentes de concesiones zonales en el País Vasco y en Asturias. ${ }^{4}$

\subsection{Sistema de concesiones zonales}

La propuesta concreta para Aragón consiste en establecer zonas de transporte a partir de las rutas estructurantes (mapa 2), que son las que conectan entre sí las ciudades, es decir, la capital regional, las capitales provinciales y las cabeceras supra-comarcales, donde se localizan los servicios de ámbito supra-comarcal, como ya se ha indicado (apartado 3.2.). Cada zona se articula en torno a un eje, con varios nodos, que en su mayor parte coinciden con las cabeceras de las rutas de centralidad. En estos nodos los núcleos de las áreas de influencia respectivas se conectan a la ruta axial mediante transbordos coordinados y así sus habitantes pueden acceder a los núcleos urbanos. Dentro de cada zona el transporte escolar se coordina con el regular, ampliando todo lo posible el número de rutas mixtas en régimen de reserva de plaza.

La propuesta final de zonas de transporte, resultado del proceso iterativo descrito en el apartado de metodología, se recoge en el mapa 5. Puede apreciarse un marcado componente radial, con centro en Zaragoza, la capital regional, como corresponde a la estructura primacial del sistema aragonés de asentamientos. Las dos zonas radiales más importantes son las que tienen como ejes los tramos de autovía que conectan Zaragoza con las otras dos capitales de provincia: Teruel, al sur, y Huesca, al norte, prolongándose este hasta Jaca.

Otras cuatro zonas radiales conectan Zaragoza con cinco de las cabeceras supra-comarcales. Al oeste hay dos: la más meridional conecta Zaragoza y Calatayud, siguiendo la autovía nacional II; la más septentrional se articula desde Zaragoza en torno al eje de la autopista A-68, que se bifurca en dirección a Tarazona y Ejea de los Caballeros. Al este hay otras dos, estructuradas en torno a los ejes que conectan Zaragoza con Fraga y Alcañiz, pequeñas ciudades que aun perteneciendo a las provincias de Huesca y Teruel, respectivamente, tienen más vinculación con la capital regional que con las de su provincia; el primer eje sigue la carretera radial II y el segundo la carretera nacional 232.

Las dos zonas restantes no se vinculan directamente a Zaragoza, sino a las ciudades de Huesca y Teruel. La primera se articula en torno al eje del somontano pirenaico, que dispone de autovía, aunque algunos tramos están sin terminar; conecta Huesca con las cabeceras supra-comarcales de Barbastro y Monzón. La última zona no tiene un eje claramente definido: Teruel es la única ciudad de la misma, a la que sólo acompañan algunas pequeñas cabeceras comarcales; es el área más despoblada y más aislada de Aragón. Se barajaron distintas opciones para esta zona, como integrarla en el eje radial Zaragoza-Teruel, pero resultaba un espacio demasiado extenso y difícil de articular teniendo en cuenta las infraestructuras viarias, o conformar un eje secundario entre Zaragoza y Teruel por Utrillas y Belchite, pero el análisis reveló su escasa viabilidad.

Un principio general aplicado en la propuesta de organización de cada una de las zonas ha sido que todo núcleo de población debería, como mínimo, mantener el mismo nivel de calidad de que ya dispone en servicios de transporte, mejorándolo en todo lo posible. Como ejemplo concreto de propuesta se presenta la de la zona Zaragoza-Calatayud-Valle del Jalón.

4. Orden de la Diputación Foral de Guipúzcoa, de 2 de agosto de 2002, publicada en el Boletín Oficial de Guipúzcoa del 30 de agosto de 2002. Resolución de 30 de noviembre de 2009, del Director General del Consorcio de Transportes de Asturias, publicada en el Boletín Oficial del Principado de Asturias del 4 de enero de 2010. 


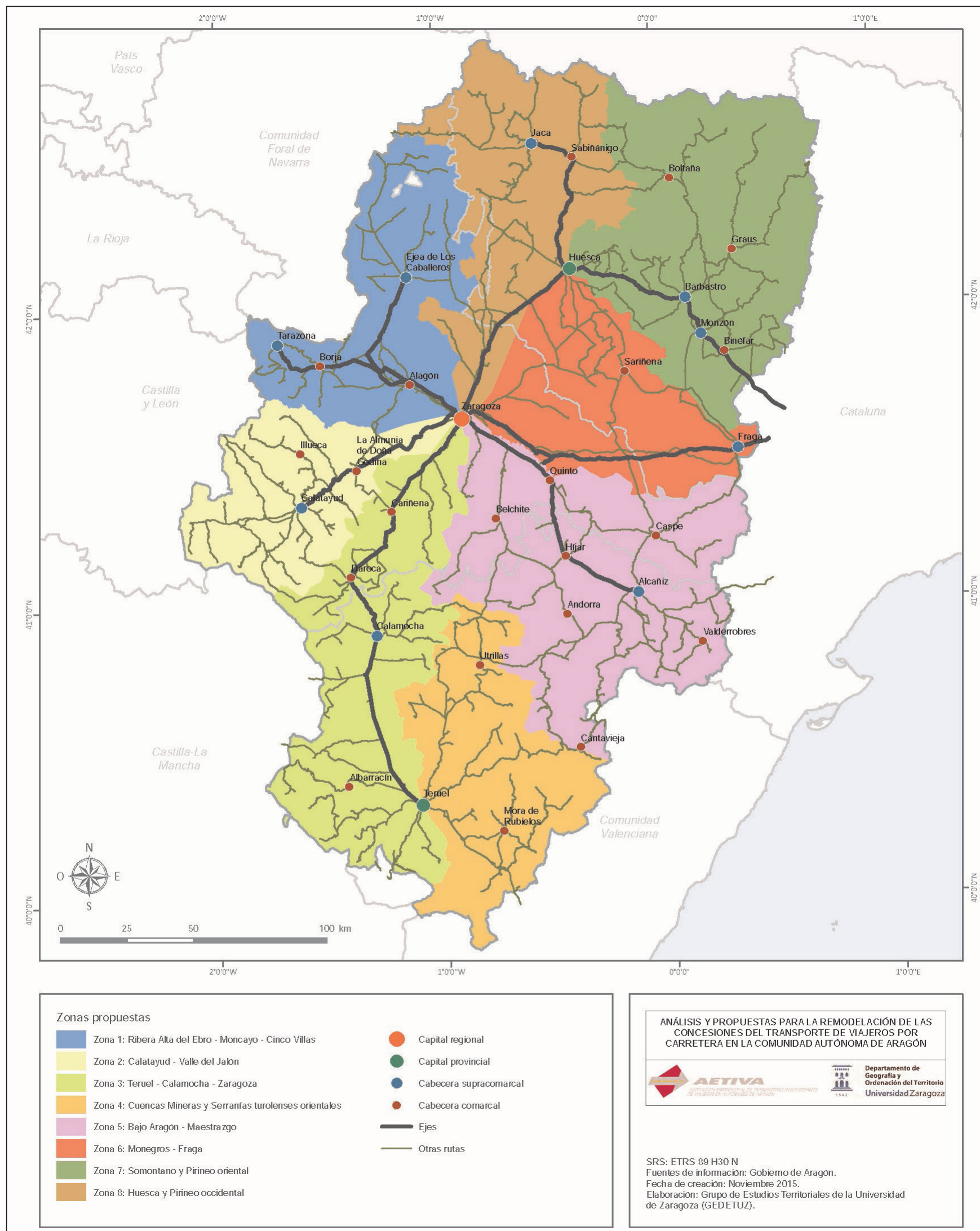

Mapa 5. Propuesta de zonas de transporte para Aragón.

Fuente: Elaboración propia. 
El mapa 6 muestra la estructura básica de la zona con su jerarquía de líneas y de nodos. En cuanto a estos últimos encontramos tres niveles jerárquicos:

a. Nodos principales, que se corresponden con las cabeceras comarcales: Calatayud, La Almunia de Doña Godina e Illueca. En el caso de Aragón se trata de capitales administrativas, como se ha indicado en el apartado 3.2, en las que se ubican los servicios públicos de base. Además, la concentración en ellas de equipamientos comerciales y servicios a la población privados les confiere centralidad y los convierte en lugares atractivos para los habitantes de los núcleos de su entorno.

b. Nodos de trasbordo: Ariza, Alhama de Aragón, El Frasno y Épila. Son lugares situados en cruces de carreteras, cuya posición estratégica en relación con el eje principal los hace idóneos para organizar en ellos transbordos coordinados.

c. Otros nodos, que son los núcleos rurales donde finalizan las rutas escolares, con lo que se abre la posibilidad de trasbordo a líneas regulares. En una buena parte de los casos estos núcleos disponen también de centro de salud.

La estructura de las rutas o líneas es la siguiente:

a. Una línea principal o línea estructurante: Zaragoza-Calatayud

b. Tres líneas secundarias: Illueca-Calatayud, Ariza-Calatayud y Calatayud-Daroca

c. 19 rutas de centralidad, con destino en los nodos principales o de trasbordo.

d. 24 rutas integradas de transporte escolar que finalizan en otros núcleos.

Como ya se ha adelantado, la ruta principal une las ciudades de Zaragoza y Calatayud, pasando por una cabecera comarcal importante, La Almunia de Doña Godina. Esta ruta presta servicio a 32.612 habitantes y para ella se propone una frecuencia de 10 expediciones por sentido en día laborable. En las rutas principales o estructurantes de cada zona se propone un aumento de frecuencias, que se fundamenta en una mayor afluencia de viajeros derivada de una mejor coordinación horaria con las rutas de menor rango. Además, en este caso concreto, el aumento de frecuencias también se sustenta en la eliminación de una importante restricción, pues el tráfico actual entre Calatayud y Zaragoza es operado por una empresa diferente a la de la línea entre La Almunia y Zaragoza.

Las líneas secundarias son de dos tipos. El primero incluye rutas de centralidad que atienden los flujos de mayor importancia; son dos, que discurren íntegramente por la zona, afluyendo al eje en determinados nodos: Ariza-Ateca-Calatayud, por la parte occidental, siguiendo la autovía nacional II, y la que recorre la comarca del Aranda, pasando por su capital Illueca, hasta Calatayud. El segundo tipo de rutas secundarias incluye las que conectan con nodos principales situados en zonas de transporte vecinas, como la Calatayud-Daroca, pasando por Morata de Jiloca, cuya necesidad deriva del hecho de que la comarca de Daroca está incluida en el sector sanitario de Calatayud, donde se ubica el hospital de referencia, con los servicios anejos de especialidades médicas en consulta externa. La mejora de las líneas secundarias se fundamenta en el ahorro de kilómetros realizado por la eliminación de restricciones de tráfico, la creación de puntos de trasbordo o la eliminación de solapes con las líneas principales. La ruta entre Illueca y Calatayud es un buen ejemplo de la propuesta planteada, ya que gracias a la instauración del nodo de trasbordo de El Frasno, los viajeros de la línea pueden trasbordar en dirección a Zaragoza. Esto ha permitido eliminar la única expedición por sentido de esta zona con Zaragoza, sin perder oportunidades de viaje.

El mapa se completa con otras rutas de menor jerarquía, cuya función es acercar a los viajeros a alguno de los nodos, donde podrán terminar viaje si el motivo del mismo es utilizar los servicios que en él se ofrecen, o continuar, mediante transbordo coordinado, hacia un núcleo de población de mayor rango jerárquico. Este tipo de rutas adolece de dos problemas que se retroalimentan: un bajo número de viajeros, y un bajo número de expediciones. Para paliar el primero se propone movilizar un mayor número de escolares mediante el uso de la reserva de plaza. En cuanto al segundo, estas rutas de centralidad ven mejorado su nivel de frecuencia gracias a la integración del transporte escolar.

Así las rutas escolares en integración amplían durante el curso escolar el sistema de transporte regular sin coste alguno, mejorando la calidad del servicio en aquellas áreas de mayor carácter rural, que es preci- 


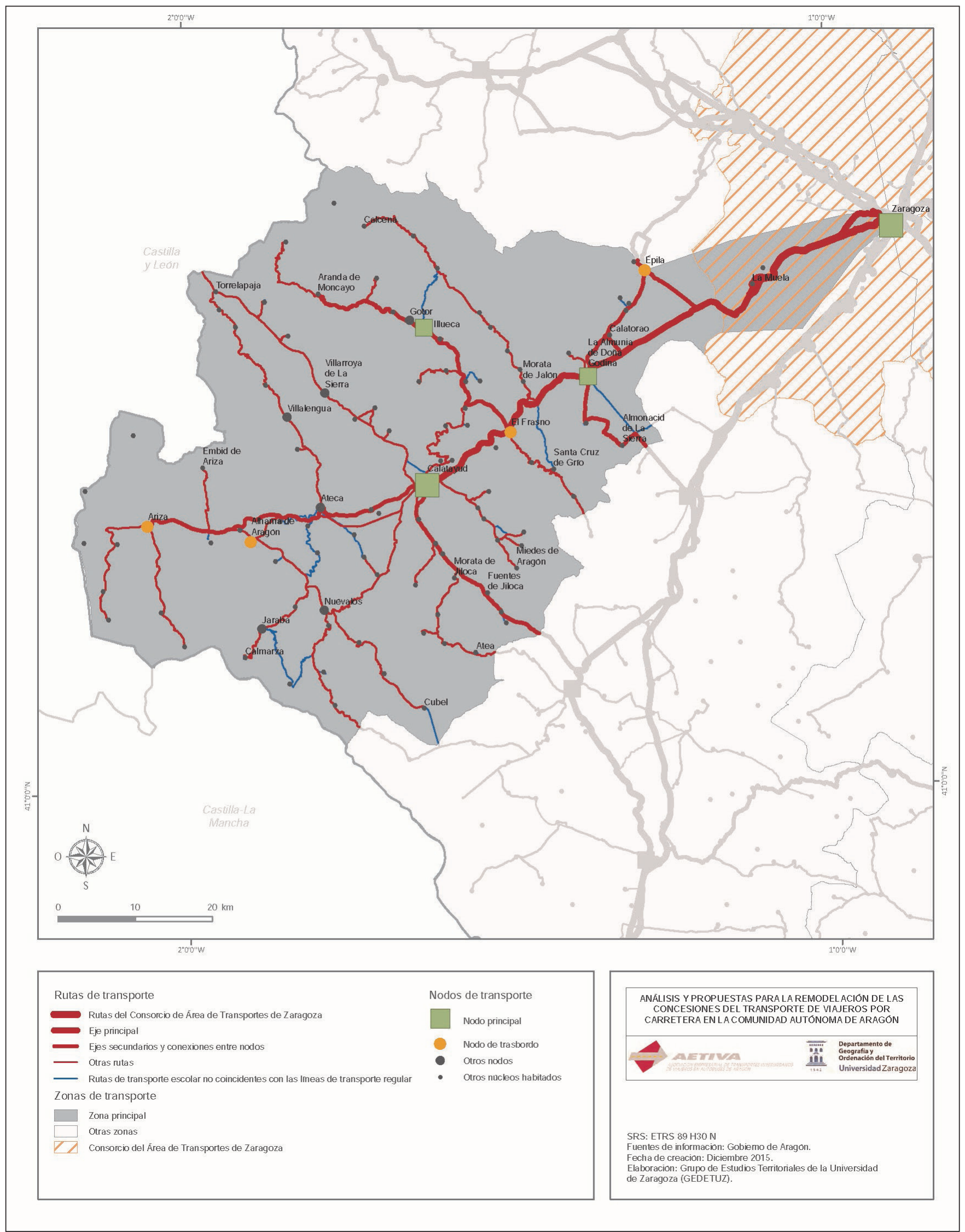

Mapa 6. Nodos y rutas planificados para la zona Zaragoza-Calatayud-Valle del Jalón. Fuente: Elaboración propia. 
samente donde más se necesita. Estas rutas suponen, por un lado, un aumento de la frecuencia hacia los núcleos de destino del transporte escolar, donde existen otros servicios de transporte regular y, por otro, la creación de nuevos itinerarios que atienden a núcleos muy pequeños que carecen de servicio regular en la actualidad, con lo que garantizarían unos servicios mínimos de lunes a viernes durante todo el curso escolar. A escala de toda la comunidad autónoma, estas rutas mejoran las oportunidades de viaje para más de 50.000 personas que residen en pequeños núcleos, dando servicio además a 157 núcleos que ahora no tienen transporte regular, en los que en 2018 vivían 8.265 personas.

Las rutas programadas cubren la práctica totalidad de la zona, pero aún quedan algunos pequeños núcleos de población sin servicio. La solución que se propone para ellos es la implantación de un sistema de transporte a la demanda, término que "ha sido crecientemente aplicado en los últimos diez años a un nicho de mercado que sustituye y complementa el transporte convencional allá donde la demanda es pequeña y a menudo está dispersa por una extensa área" (Brake, J. et al, 2004, 324). El transporte a la demanda está ampliamente extendido por diversos países, como el Reino Unido (Laws, R. et al, 2009), y se ha implementado también en regiones españolas, como Castilla y León (Delgado, J.M. y Martínez, L.C., 2016), semejante a Aragón en cuanto a densidad demográfica y estructura territorial. El transporte a la demanda en esencia consiste en que el demandante comunica a la empresa su necesidad de viajar y ésta le ofrece la mejor opción dentro de su oferta, normalmente alargando hasta la localidad del viajero una de las expediciones que llega o parte de alguna localidad vecina. El aviso debe hacerse con una antelación razonable, mayor o menor en función del sistema que se implemente: los centros coordinadores disponen de un servicio de atención telefónica; además, una buena aplicación informática puede transmitir en tiempo real la demanda al autobús, junto con las instrucciones para el conductor.

Recapitulando, tal como se ha visto en el caso de Calatayud-Zaragoza, cada zona se estructura en torno a una ruta principal que conecta entre sí las ciudades. A esa ruta principal afluyen las demás en determinados nodos, donde se efectúan transbordos coordinados que permiten continuar viaje hasta los destinos principales. Dentro de cada zona el transporte escolar se coordina con el regular, ampliando todo lo posible el número de rutas mixtas: la reserva de plaza permite suprimir numerosas rutas escolares normales, sin disminuir las oportunidades de viaje de los usuarios de transporte regular ni de los alumnos. La integración, por su parte, amplía durante el curso escolar el sistema de transporte regular sin coste alguno. La implementación de sistemas de transporte a la demanda permite conectar al resto de núcleos en condiciones satisfactorias para usuarios y empresas.

Al estimar los parámetros de la propuesta, para compararlos con los de la situación actual, se ha partido de los siguientes supuestos: el primero de ellos, teniendo en cuenta las proyecciones demográficas recogidas en el apartado 3.1., es que el número de viajeros apenas variará, experimentando sólo un ligero crecimiento del 1,4\%, efecto esperable de la coordinación de horarios, la eliminación de restricciones, la creación de nuevos servicios y la puesta en marcha del transporte a la demanda. El segundo supuesto es que los costes unitarios se van a mantener constantes, si bien se trata de una hipótesis conservadora, pues las economías de escala derivadas de la organización zonal previsiblemente producirán una reducción de los mismos. El tercero es que el precio de los billetes se mantendrá también constante. En el cuadro 1 se recogen los resultados de la comparación de dicha estimación con la situación actual.

El número de viajeros apenas crecerá, pero se producirá un trasvase importante del transporte escolar al regular, gracias a la expansión de la reserva de plaza para estudiantes de secundaria en los autobuses de línea; ello permitirá aprovechar mejor los recursos disponibles, con la consiguiente reducción de costes. El número de kilómetros recorridos en un año por los autobuses disminuirá en una octava parte, gracias a la sustitución de líneas de transporte escolar específicas por la reserva de plaza; se trata de un ahorro considerable, que además no repercutirá negativamente en la calidad, pues en la propuesta no se ha suprimido -sólo reorganizado- ninguno de los servicios existentes. Los costes de explotación del sistema se reducirán en la misma proporción, teniendo en cuenta el supuesto de partida de costes unitarios invariables.

La recaudación por tarifa disminuirá casi un 5\%, como efecto combinado del ligero incremento del número de viajeros, la fuerte reducción de los kilómetros recorridos y el supuesto de precios constantes. Conviene destacar en este aspecto que la recaudación subirá un $25 \%$ en el transporte regular, pero se reducirá un 
Cuadro 1. Variación de los principales parámetros entre la situación actual y la propuesta zonal (\%).

\begin{tabular}{|c|c|c|c|c|c|c|c|}
\hline & $\begin{array}{l}\text { Tipo de } \\
\text { transporte }\end{array}$ & Viajeros & Kilómetros & $\begin{array}{l}\text { Costes de } \\
\text { explotación } \\
(€)\end{array}$ & $\begin{array}{l}\text { Recaudación } \\
\text { por tarifa }(€)\end{array}$ & Déficit (€) & $\begin{array}{c}\text { Recaudación } \\
\text { sobre costes } \\
\text { (\%) }\end{array}$ \\
\hline \multirow{3}{*}{$\begin{array}{l}\text { Situación } \\
\text { de partida } \\
\text { (2013) }\end{array}$} & Regular & 3.974 .506 & 12.734 .106 & 20.796 .382 & 13.033 .084 & -7.763 .297 & 62,67 \\
\hline & Escolar & 4.581 .846 & 8.454 .248 & 13.436 .042 & 13.436 .042 & 0 & 100 \\
\hline & Total & 8.556 .352 & 21.188 .354 & 34.232 .424 & 26.469 .127 & -7.763 .297 & 77,32 \\
\hline \multirow{3}{*}{$\begin{array}{l}\text { Propuesta } \\
\text { (2017) }\end{array}$} & Regular & 5.900 .030 & 12.780 .939 & 21.016 .234 & 16.289 .001 & -4.727 .233 & 77,51 \\
\hline & Escolar & 2.778 .556 & 5.711 .032 & 8.929 .079 & 8.929 .079 & 0 & 100 \\
\hline & Total & 8.678 .586 & 18.491 .970 & 29.945 .313 & 25.218 .080 & -4.727 .233 & 84,21 \\
\hline \multirow{3}{*}{$\begin{array}{l}\text { Tasa de } \\
\text { variación (\%) }\end{array}$} & Regular & 48,45 & 0,37 & 1,06 & 24,98 & $-39,11$ & 23,68 \\
\hline & Escolar & $-39,36$ & $-32,45$ & $-33,54$ & $-33,54$ & - & 0 \\
\hline & Total & 1,43 & $-12,73$ & $-12,52$ & $-4,73$ & $-39,11$ & 8,91 \\
\hline
\end{tabular}

Fuente: Gobierno de Aragón: Transporte público interurbano de viajeros por carretera en Aragón [https://opendata. aragon.es/datos/catalogo/dataset/transporte-regular-de-viajeros-por-carretera-en-aragon] y elaboración propia.

33,5\% en el escolar. Téngase en cuenta a este respecto que la administración pública sufraga íntegramente los billetes de los escolares, sea cual sea el sistema en que viajen, pero el sistema de reserva de plaza es más económico (Badía, R., 2016), por lo que su expansión supone un ahorro para el erario público. ${ }^{5}$

Combinando costes y recaudación resulta una caída del déficit de explotación estimada en un 39\%, pues la reducción de costes será superior a la de la recaudación. Esta caída afectará al transporte regular, pues en el escolar no tiene sentido hablar de déficit, dado que el coste lo sufraga íntegramente la administración pública. Con ello la proporción de los costes cubierta por la recaudación pasaría del 63 al 78\% en el transporte regular o, considerando las cifras globales, del 77 al $84 \%$.

Con los supuestos de partida, especialmente el de garantizar unos servicios con al menos la misma calidad que los actuales, no es posible eliminar por completo el déficit de explotación, aunque sí reducirlo considerablemente. En la situación de partida las administraciones públicas regionales aportan 4,2 millones de euros en subvenciones a las empresas, pero éstas aún tienen que cubrir un déficit de 3,5 millones. El déficit estimado en la propuesta zonal es de 4,7 millones de euros, que se podría cubrir casi íntegramente manteniendo el volumen actual de las aportaciones públicas.

\subsection{La propuesta zonal y el plan del gobierno de aragón}

Como ya se ha indicado (nota 1), la propuesta aquí presentada es el producto final de un contrato de I+D+i firmado por la asociación de empresarios AETIVA y la Universidad de Zaragoza. Una vez redactado el informe por parte del equipo investigador, los empresarios lo pusieron a disposición del Gobierno regional. Este realizó su propio estudio, pero no pudo tener elaborado a tiempo el nuevo mapa de concesiones, prorrogando las vigentes, que caducaban en 2017. En octubre de 2018 publicó una resolución en la que sometía al trámite de información pública el nuevo mapa concesional, desglosado en 19 anteproyectos de explotación del servicio (Gobierno de Aragón, 2018), no habiéndose dado ningún otro paso desde entonces hasta las

5. En el diagnóstico, utilizando datos del Gobierno de Aragón, pudo determinarse que el coste medio por alumno de secundaria y día en régimen de reserva de plaza ascendía a 3,39 euros, frente a 4,76 en una ruta escolar normal. 
elecciones autonómicas de 26 de mayo de 2019; la formación del nuevo Gobierno seguramente retrasará en varios meses el desarrollo del proceso.

En la citada resolución se asume el modelo de concesión zonal, pues cada uno de los 19 anteproyectos corresponde a un "área" claramente delimitada. Estas áreas se dividen en dos grandes grupos: 4 de carácter metropolitano, ubicadas en el entorno de Zaragoza, y 15 interurbanas, que se reparten el resto del territorio regional. Algunas de estas últimas coinciden en alto grado con las de nuestra propuesta (mapa 7), siendo la principal diferencia la forma de considerar el área metropolitana de Zaragoza, que nosotros no hemos segregado de cada una de las zonas radiales en torno a la ciudad. Se aprecian coincidencias sustanciales en las zonas 1 (Jaca-Huesca-Zaragoza), 11 (Teruel-Calamocha-Zaragoza) y 13 (Calatayud-Zaragoza), si bien en la segunda no se incluye la comarca de Albarracín y la última incorpora el bajo valle del Jalón. Las restantes zonas de nuestra propuesta aparecen en la del Gobierno fragmentadas en dos o más, aunque grosso modo coinciden los límites agregados.

La justificación del modelo zonal que hace el Gobierno de Aragón se fundamenta en la generación de economías de escala derivadas de la concentración de contratos y la eliminación de las duplicidades de

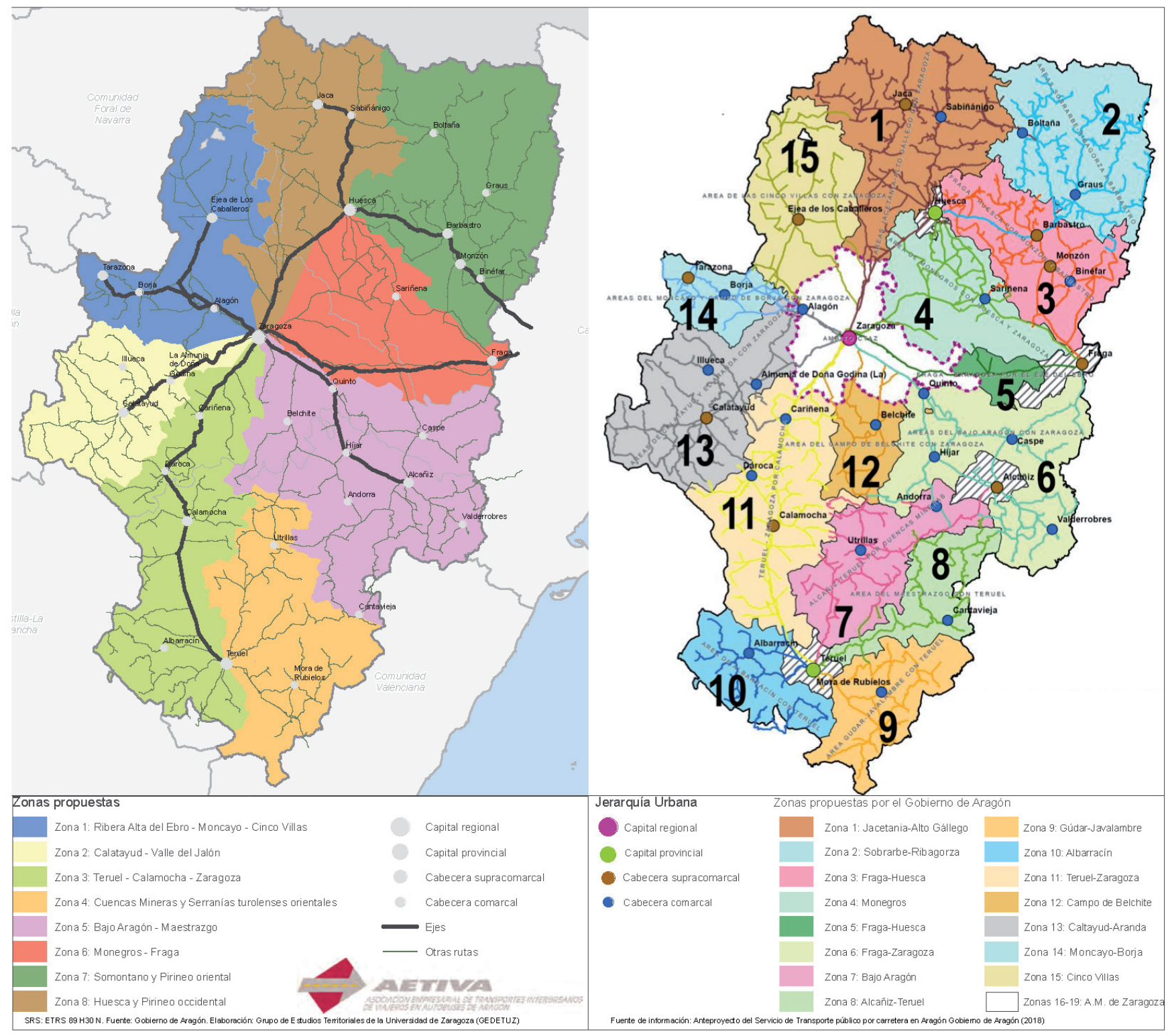

Mapa 7. Zonas de transporte propuestas y futuro mapa concesional de Aragón. Fuente: Gobierno de Aragón (2018) y elaboración propia. 
tráfico. Es una línea argumental plenamente coincidente con la desarrollada en este artículo. No obstante, el Gobierno regional ha optado por una concentración menor que la propuesta por nosotros, lo que traerá consigo que la generación de economías de escala será más modesta y, sobre todo, que no se podrán eliminar muchas duplicidades de tráfico. Esta afirmación puede ilustrarse con los dos ejemplos siguientes:

En primer lugar, la delimitación de las zonas 2 y 3 parte en dos un mismo espacio funcional, dando lugar a una fuerte asimetría: en la zona 3 es donde se localizan el eje viario principal y las centralidades de mayor rango (Huesca, Barbastro y Monzón); la zona 2 es un área de montaña de baja densidad demográfica y pequeños núcleos de población, por lo que resulta muy difícil generar en ella economías de escala significativas. Por otra parte, esta zona depende funcionalmente de Barbastro, donde se localiza, entre otros servicios importantes, el hospital de referencia, por lo que lo más lógico sería que se integrase en la misma zona de transporte que la ciudad de la que depende, tal como nosotros hemos propuesto.

El segundo ejemplo es el de las zonas 14 y 15. Con esa división no se podrán evitar duplicidades de tráfico, porque las líneas de Tarazona a Zaragoza y de Ejea de los Caballeros a Zaragoza coinciden en una buena parte de su recorrido, aunque en el anteproyecto se suprimen las restricciones de tráfico. Esa es la razón de que nosotros propusiéramos integrarlas en una sola zona, porque de esa manera se podrían organizar las rutas con una mayor coordinación, recurriendo a transbordos que mejorarían las posibilidades de viaje con la capital regional y entre las dos cabeceras supra-comarcales.

La zonificación de la propuesta del Gobierno de Aragón hace que las situaciones descritas en los ejemplos anteriores se repitan en otras zonas: la generación de economías de escala significativas queda en entredicho en las zonas 4, 7, 8, 9, 10 y 12, donde la densidad de población es muy baja (mapa 1).

La duplicidad de tráficos afectará claramente a todas las zonas que rodean el espacio metropolitano de Zaragoza. Consciente de este problema, la resolución del Gobierno establece lo siguiente: "en el ámbito del Consorcio de Transportes del Área de Zaragoza se planificarán las líneas pasantes interurbanas de tal manera que complementen los servicios consorciales planificados por el propio CTAZ, alcanzando conjuntamente por ambos tipos de líneas, e incluso mejorando, los objetivos definidos en las Directrices Metropolitanas de Movilidad de Zaragoza" (Gobierno de Aragón, 2018). De donde se desprende que la coordinación estará orientada a la consecución de los objetivos del espacio metropolitano, lo cual parece implicar la subordinación de los espacios no metropolitanos.

Por otra parte, y esta es una diferencia radical respecto a nuestra propuesta, no se plantea la gestión conjunta de transporte regular y escolar, que sólo se menciona como una mera posibilidad para un futuro indeterminado: "Todo esto sin perjuicio de que en un futuro pudieran integrarse los servicios regulares de uso especial (transporte escolar de titularidad pública)" (Gobierno de Aragón, 2018). Sí se hace mención de las líneas en reserva de plaza existentes, que continuarán como tales.

Al margen de las observaciones críticas previas, la propuesta del Gobierno de Aragón va a suponer una mejora significativa en cuanto a la población y los núcleos atendidos por el transporte público, cuyo número se incrementará hasta el punto de que todos los núcleos de más de 10 habitantes tendrán al menos un servicio por semana. Para estos casos se prevé el establecimiento de sistemas de transporte a la demanda.

Como elemento final queda la valoración económica. Es difícil hacer una comparación precisa y rigurosa entre nuestra propuesta y la del Gobierno de Aragón, habida cuenta de que los supuestos de partida son diferentes: el Gobierno ha calculado los costes al momento presente y fijado las tarifas que considera adecuadas, mientras que en nuestra propuesta asumíamos costes y tarifas constantes respecto a la situación de partida. No obstante, vale la pena tomar en consideración, a modo de ejemplo, la zona de Calatayud, que es una de las más parecidas en ambos casos (cuadro 2).

El Gobierno de Aragón asume que el sistema de transporte va a generar déficit, que se compromete a sufragar íntegramente. Esto contrasta con el planteamiento tradicional de las concesiones de líneas de autobús, que se llevaban a cabo "a riesgo y ventura", planteamiento que ha cambiado últimamente al afianzarse la consideración del transporte como un derecho que la administración pública debía garantizar y, en caso necesario, sufragar. El déficit que está dispuesto a asumir en este caso es superior a la mitad de los costes de explotación. Nuestra propuesta arroja un déficit y, en consecuencia, una necesidad de financiación pública inferior. Aunque las cifras no sean estrictamente comparables, como ya se ha indicado, la diferencia resulta 
Cuadro 2. Valoración económica anual de la zona de transporte de Calatayud.

\begin{tabular}{|c|c|c|c|}
\hline & \multirow{2}{*}{ Gobierno de Aragón } & \multicolumn{2}{|c|}{ Propuesta propia } \\
\hline & & Transporte regular & Transporte total* \\
\hline Costes de explotación & 2.272 .559 & 1.961 .035 & 2.720 .207 \\
\hline Ingresos tarifarios & 1.006 .793 & 1.667 .788 & 2.426 .960 \\
\hline Déficit = Subvención & 1.265 .766 & 293.247 & 293.247 \\
\hline Ingresos sobre costes (\%) & 44,3 & 85,0 & 89,2 \\
\hline Subvención sobre costes (\%) & 55,7 & 15,0 & 10,8 \\
\hline
\end{tabular}

*Incluye transporte regular y transporte escolar; este último no se contempla en la propuesta del Gobierno de Aragón. Fuente: Gobierno de Aragón (2018) y elaboración propia.

coherente con las observaciones previamente realizadas sobre las economías de escala, las duplicidades de tráficos, la menor utilización de trasbordos y, sobre todo, la no integración de transporte escolar y regular. Al final todo se traduce en unos costes más elevados, que repercutirán en el erario público.

\section{CONCLUSIONES}

La movilidad es un derecho ciudadano, cuya garantía es responsabilidad de la administración pública, que debe diseñar un sistema de transporte colectivo que satisfaga las necesidades de la población, especialmente la de quienes no tienen posibilidades de acceso a medios de transporte privados (Belintxon, U., 2016; Farrington, J. y Farrington, C., 2005). El Gobierno de Aragón, ante la caducidad simultánea de todas las concesiones de tráfico interno, trabaja en su remodelación, contando con un estudio previo de los empresarios.

Este estudio ha confirmado la dificultad de organizar un buen servicio de transporte en zonas de baja densidad demográfica (Gutiérrez, J., 1988). Como revela el diagnóstico, la calidad del servicio es buena para la mayor parte de la población aragonesa, pero claramente insuficiente en casi la mitad del territorio, precisamente el menos densamente poblado. Otros trabajos han llegado a conclusiones similares para el caso de otras áreas españolas, como Castilla y León (Delgado, J.M. y Martínez, L.C., 2016), Navarra (Pons, J.J. y Betelu, A., 2004) o la provincia de Albacete (Fernández, F., 1999).

Se ha demostrado que es posible mejorar la calidad del sistema reduciendo a la vez los costes de explotación. Los sistemas basados en concesiones lineales presentan disfunciones importantes, lo que implica un aprovechamiento ineficiente de los recursos disponibles, que repercute en un peor servicio a la población y un mayor coste económico. La clave está en un sistema basado en contratos de gestión zonales, que permite organizar de forma flexible y coordinada las líneas de autobús. La jerarquización de rutas, la elección de nodos estratégicos y el recurso sistemático a transbordos con horarios coordinados crea nuevas oportunidades de viaje para las personas (Carbonell, M., 2018), reforzando destinos ya existentes y creando otros nuevos, con un ahorro considerable de kilómetros y costes de explotación.

La gestión conjunta del transporte regular y el escolar evita duplicidad de rutas de autobús: la generalización de la reserva de plazas escolares en el transporte regular permite ahorrar muchos kilómetros, con la consiguiente reducción de costes. La admisión de pasajeros regulares en líneas de transporte escolar crea nuevas oportunidades de viaje precisamente en los espacios rurales de menor densidad de población, sin generar costes adicionales (Badía, R., 2016; Carbonell, M., 2018). El sistema se completa con la implantación del transporte a la demanda, que permite llegar prácticamente a todas partes cuando es necesario, en condiciones razonables para usuarios y empresas (Delgado, J.M. y Martínez, L.C., 2016; Laws, R. et al., 2009).

El sistema de contratos de gestión zonales ha sido asumido por el Gobierno de Aragón, que se incorpora así a otros que ya lo han hecho, como el de Asturias. El proyecto de nuevo mapa concesional supone una 
mejora respecto a la situación actual, pero nace con poca ambición, pudiendo pronosticarse que no resolverá bien los problemas, sobre todo porque no incorpora el transporte escolar, que seguirá siendo una red paralela.

Esa falta de ambición tiene efectos económicos, que el Gobierno reconoce en forma de déficit de explotación en las zonas, aceptando que ese déficit no debe recaer sobre las empresas, como sucede ahora parcialmente, sino que debe ser cubierto por el erario público, pues se trata de un servicio que garantiza un derecho ciudadano. Este es el verdadero sentido del contrato de gestión, frente al tradicional de prestación de servicio a riesgo y ventura. Constituye una garantía para las empresas y obliga a la administración a ser rigurosa en el manejo del dinero de todos. Nuestro estudio concluye también que es imposible acabar con el déficit, pero nuestros cálculos apuntan a una reducción importante respecto a la situación actual, con unas cifras muy inferiores a las del proyecto del Gobierno. La causa es que la integración del transporte escolar con el regular y la delimitación de zonas de mayor extensión y coherencia interna tienen como resultado una notable reducción de costes. Este mayor ahorro de recursos podría utilizarse para reforzar el sistema aquí propuesto bajo los principios anteriormente expuestos, lo que mejoraría la accesibilidad rural.

\section{REFERENCIAS}

Badía R. (2016). Las posibilidades de integración del transporte regular y escolar en Aragón. Geographicalia, 68, 1-24. doi: https://doi.org/10.26754/ojs_geoph/geoph.2016681579

Bachiller-Martínez, J.M. y Molina de la Torre, I. (2014). La localización de servicios y equipamientos en el medio rural: claves para la articulación territorial de Castilla y León. Ería, 93, 77-100.

Belintxon-Martin, U. (2016). Derecho internacional privado y transporte de viajeros por carretera: algunas cuestiones sobre jurisdicción y ley aplicable. Cuadernos de Derecho Transnacional, 8(1), 17-35.

Boquete-Sánchez, D. (2018). Transporte escolar en Galiza. Outra oportunidade perdida. Revista galega de educación, 72, 40-42.

Brake, J., Nelson, J.D. \& Wright, S. (2004). Demand responsive transport: towards the emergence of a new market segment. Journal of Transport Geography, 12, 323-337. doi: https://doi.org/10.1016/j.jtrangeo.2004.08.011

Carbonell-Alemany, M. (2018). Estudio y diseño de una red de transporte público interurbano en las comarcas de “L'Alcoià” y "El Comtat". 3C Tecnología: glosas de innovación aplicadas a la pyme, 7(1), 20-42. doi: https://doi.org/10.17993/3ctecno.2018.v7n1e25.20-42

Comisión Europea (1999). Estrategia territorial europea. Hacia un desarrollo equilibrado y sostenible del territorio de la UE. Luxemburgo: Oficina de Publicaciones de la Unión Europea.

Delgado-Urrecho, J. M. y Martínez Fernández, L.C. (2016). El transporte a la demanda como sistema de movilidad alternativo en áreas rurales de baja densidad demográfica: el caso de Castilla y León. Boletín de la Asociación de Geógrafos Españoles, 72, 195-220. doi: https://doi.org/10.21138/bage.2337

Delgado-Urrecho, J. M. (2018). Más allá del tópico de la España vacía: una geografía de la despoblación. En Informe España 2018 (pp. 232-295). Madrid: Universidad Pontificia Comillas, Catedra J.M. Martin Patino.

Escolano-Utrilla, S. y De la Riva-Fernández, J. (2003). Marco conceptual y metodológico del estudio de los procesos de despoblación. En Escolano Utrilla, S. y De la Riva Fernández, J. (Ed), Despoblación y ordenación del territorio (pp. 7-14). Zaragoza: Institución Fernando el Católico.

Farrington, J., Farrington, C. (2005). Rural accessibility, social inclusion and social justice: towards conceptualisation. Journal of Transport Geography, 13, 1-12. doi: https://doi.org/10.1016/j.jtrangeo.2004.10.002

Fernández-Santamaría, F. (1999). Transporte público de viajeros por carretera y accesibilidad en la provincia de Albacete. Ensayos. Revista de Estudios de la Escuela Universitaria de Magisterio de Albacete, 14, 27-41.

Garrido-Palacios, J. (2002). Política de transporte y accesibilidad en Europa. Estudios Geográficos, 63 (246), 49-67. doi: https://doi.org/10.3989/egeogr.2002.i246.260

Gobierno de Aragón (2014). Estrategia de Ordenación Territorial de Aragón. Boletín Oficial de Aragón, 243 (12/12/2014).

Gobierno de Aragón (2018). Resolución de 29 de octubre de 2018, de la Dirección General de Movilidad e Infraestructuras, por la que se aprueban y someten al trámite de información pública los diecinueve anteproyectos de explota- 
ción del servicio de Transporte Público Regular de Viajeros por Carreteras de Aragón. Boletín Oficial de Aragón, 213 (05/11/2018).

Guirao, B. y Briceño, D. (2006). First study on mobility for a medium size town: Ciudad Real, a Spanish experience. WIT Transactions on Ecology and the Environment, 93. Recuperado de https://www.witpress.com/elibrary/wit-transactions-on-ecology-and-the-environment/93/16893 Último acceso: 12 de marzo de 2019. doi: https://doi.org/10.2495/ SC060621

Gutiérrez-Puebla, J. (1988). Accesibilidad y transporte rural. Una perspectiva social. Revista del Ministerio de Transportes, Turismo y Comunicaciones, 34, 27-40. doi: https://doi.org/10.3989/egeogr.2001.i242.295

Gutiérrez-Puebla, J. (2001). Escalas espaciales, escalas temporales. Estudios Geográficos, 62 (242), 92-97.

Laws, R., Enoch, M. \& Ison, S. (2009). Demand Responsive Transport: a Review of Schemes in England and Wales. Journal of Public Transportation, 12 (1), 19-37. doi: https://doi.org/10.5038/2375-0901.12.1.2

Lopez-Lara, E. (1989). Sobre la articulación a escala intermedia en Andalucía. Análisis de la estructura empresarial y territorial de las líneas de transporte público de pasajeros por carretera. Revista de Estudios Andaluces, 13, 79-101. https://doi.org/10.12795/rea.1989.i13.05

Martínez Sánchez-Mateos, H. S. (2012). La accesibilidad regional y el efecto territorial de las infraestructuras de transporte. Aplicación en Castilla-La Mancha. Boletín de la Asociación de Geógrafos Españoles, 59, 79-103.

Mora-Aliseda, J., Nogales-Galán, J. M., Gutiérrez-Gallego, J. A. y Cortés-Ruiz, T. (2003). Aplicación de técnicas SIG en la planificación del transporte por carretera en Extremadura (España). Finisterra, 38 (75), 67-83. doi: https://doi. org/10.18055/Finis1580

Pérez-Díaz, J., Abellán-García, A. (2018). Envejecimiento demográfico y vejez en España. Panorama Social, 28, 11-47.

Pons-Izquierdo, J.J. y Betelu-Corcuera, A. (2004). Accesibilidad territorial al transporte público interurbano de viajeros en Navarra. En Quinto Congreso de Economía de Navarra (pp. 216-234). Pamplona: Gobierno de Navarra.

Rojo-Arce, M. (2011). Modelización de la interrelación entre las variables de servicio y la demanda de viajeros de autobuses de tipo interurbano. Burgos: Universidad de Burgos. Recuperado de http://riubu.ubu.es/handle/10259/162 Último acceso: 17 de mayo de 2019.

Ruiz, M., Seguí-Pons, J. M., Mateu-Lladó, J., y Martínez-Reynés, M. R. (2016). Evaluación de la equidad del servicio de transporte público: el caso de Palma de Mallorca. Estudios Geográficos, 77(281), 619-646. doi: https://doi.org/10.3989/ estgeogr.201621

Sánchez-Portales, S. (2015). El sistema concesional de transporte público regular de viajeros de uso general por carretera en Andalucía. Presente y futuro. Málaga: Universidad de Málaga. Recuperado de http://orcid.org/0000-0001-9604-8858 Último acceso: 17 de mayo de 2019

Sanchis-Deusa, M. C. (1987). Redes de transporte público de viajeros por carretera y delimitación comarcal en el país valenciano. Cuadernos de Geografía, 42, 181-192.

Serrano-Martínez, J. M. (1987). Comunicaciones terrestres y sistema urbano en la región de Murcia. Anales de Geografía de la Universidad Complutense 7, 625-633.

Smith, N., Hirsch, D. \& Davis, A. (2012). Accessibility and capability: the minimum transport needs and costs of rural households. Journal of Transport Geography, 21, 93-101. doi: https://doi.org/10.1016/j.jtrangeo.2012.01.004 